\title{
FAKTOR YANG MENINGKATKAN KINERJA PERAWAT DI RUANG RAWAT INAP: SYSTEMATIC REVIEW
}

\author{
Dwi Retnaningsih' ${ }^{1)}$, Luky Dwiantoro' ${ }^{2)}$ \\ ${ }^{1}$ Sekolah Tinggi Ilmu Kesehatan Widya Husada Semarang \\ ${ }^{2}$ Universitas Diponegoro \\ e-mail: dwiretnaningsih81@yahoo.co.id
}

\begin{abstract}
ABSTRAK
Perawat adalah tenaga kesehatan Sumber Daya Manusia yang berhubungan langsung dengan pasien dan memiliki tanggungjawab terhadap perawatan pasien. Salah satu faktor penentu keberhasilan dalam berorganisasi di rumah sakit adalah kepemimpinan yang mampu menggerakkan perawat melakukan tindakan keperawatan. Tujuan systematic review meninjau penelitian empiris yang dipublikasikan tentang gaya kepemimpinan berkaitan dengan kinerja perawat dan jenis kepemimpinan yang bisa meningkatkan kinerja perawat di ruang rawat inap. Metode dengan melakukan tinjauan sistematis melalui review jurnal tentang gaya kepemimpinan dan kinerja perawat di ruang rawat inap. Strategi pencarian data dengan google scholar, ProQuest dan Sinta, kelayakan studi penelitian dengan melakukan penelitian empiris yang merujuk pada gaya kepemimpinan dan kinerja perawat di rawat inap. Kualitas studi dengan membaca topik, desain dan instrumen penelitian. Prosedur ekstraksi data dilakukan dari hasil penelusuran artikel dengan kata kunci gaya kepemimpinan, kinerja perawat di ruang rawat inap. Literatur 10 tahun terakhir, topik sesuai, dan artikel lengkap. Berdasarkan 12 artikel yang dianalisa, 5 penelitian dengan gaya kepemimpinan demokrasi mampu memberikan hasil kinerja perawat yang baik. 1 penelitian dengan gaya kepemimpinan otoriter, 4 penelitian dengan gaya kepemimpinan kompilasi, dan 2 penelitian dengan gaya kepemimpinan konsultasi memberikan hasil kinerja perawat cukup dan baik. Kecenderungan gaya kepemimpinan otoriter dan demokratik mampu memberikan kinerja yang baik dan cukup. Jadi, tidak ada gaya kepemimpinan yang tidak baik atau buruk. Gaya kepemimpinan yang tepat diperlukan untuk menghindari pemborosan, kebingungan, dan kesalahan.
\end{abstract}

Keywords: Gaya kepemimpinan, kinerja perawat, systematic review

\begin{abstract}
Nurses are health workers who is human resources who deal directly with patients and have responsibility for patient care. One of the critical success factors in organizing at a hospital was leadership that was able to move nurses into performing nurses' actions. The purpose of the systematic review was to review published empirical research on leadership styles related to nurse performance and the types of leadership that can improve nurses' performance in the inpatient room. The method was to conduct a systematic review through a journal review of the leadership style and performance of nurses in the inpatient room. Data search strategies with Google Scholar, ProQuest and Sinta, the feasibility of a research study by conducting empirical research that refers to the leadership style and performance of nurses in hospitalization. Quality of study by reading topics, designs and research instruments. Data extraction procedure was carried out from the results of searching the article with keywords leadership style, nurse performance in the inpatient room. Literature of the past 10 years, relevant topics, and full articles. Based on 12 articles analyzed, 5 studies with a democratic
\end{abstract}


leadership style were able to provide good nurse performance results. 1 research with authoritarian leadership style, 4 research with compilation leadership style, and 2 research with consultative leadership style gives nurses good and good performance results. The tendency of an authoritarian and democratic leadership style was able to provide good and sufficient performance. So, there was no leadership style that was not good or bad. Appropriate leadership style to avoid waste, confusion, and mistakes

Keywords: Leadership style, nurse performance, systematic review

\section{PENDAHULUAN}

Unsur penunjang utama dalam pelayanan kesehatan adalah Sumber Daya Manusia (SDM). Perawat adalah tenaga kesehatan yang merupakan SDM di RS, apabila memiliki kualitas kerja kurang, mengakibatkan tidak terpenuhinya kebutuhan masyarakat akan kesehatan (Fahlevi, 2017). Salah satu SDM yang berhubungan langsung dengan pasien adalah perawat yang memiliki tanggungjawab terhadap perawatan pasien selama di RS (Windi Yunita Siwi, Titik Suerni, 2017).

Sebagai salah satu faktor penentu keberhasilan dalam berorganisasi di rumah sakit adalah kepemimpinan. Kepemimpinan adalah bagaimana kemampuan seseorang untuk menggerakkan oranglain dalam mencapai tujuan. Menggerakkan perawat dalam melakukan tindakan perawat adalah wewenang kepala ruang yang bersamasama dengan perawat dalam menerapkan budaya keselamatan pasien. Menjadi seorang pemimpin yang efektif perlu menyesuaikan gaya kepemimpinan situasional (Nivalinda et al., 2013). Seorang pemimpin mampu menjalin komunikasi dan hubungan yang efektif antara pimpinan dan tim kesehatan yang lain agar dapat melakukan tindakan sesuai dengan standar prosedur operasional yang berlaku (Alvin Nur Fadhilah, Ana Zakiyah, 2019).

Teori perilaku menjadi pedoman dalam menjalani seseorang sebagai pemimpin terhadap apa yang akan dilakukan dan menjalankan pemimpin sebagai fungsinya. Keadaan emosional yang menyenangkan ataupun tidak menyenangkan dalam melakukan pekerjaannya mencerminkan perasaan seseorang terhadap kepuasan akan pekerjaannya (Roostyowati, 2015).

Kinerja adalah perwujudan kerja yang dilakukan oleh karyawan yang biasanya dipakai sebagai dasar penilaian terhadap karyawan atau organisasi. Kinerja yang baik merupakan langkah untuk tercapainya tujuan organisasi, sehingga perlu diupayakan usaha untuk meningkatkan kinerja (Hasibuan, Malayu, 2007). Kinerja menurut Sedarmayanti adalah hasil kerja yang dapat dicapai oleh seseorang atau sekelompok orang dalam suatu organisasi, sesuai dengan wewenang dan tanggungjawab masing-masing, dalam rangka upaya mencapai tujuan organisasi bersangkutan secara legal, tidak melanggar hukum dan sesuai dengan moral maupun etika (Sedarmayanti, 2008).

Di Ruang perawatan RS, gaya kepemimpinan efektif diperlukan untuk meningkatkan kinerja karyawan sehingga mereka mau bekerja sama dan mau mengikuti perintah dengan baik sesuai dengan apa yang diiinginkan dan mendukung tercapainya tujuan pekerjaan dan tugas dalam waktu yang telah ditetapkan. Pemimpin yang dapat melaksanakan kepemimpinannya dengan persuasif, kerjasama dan memotivasi 
bawahannya untuk berpartisipasi dalam pengambilan keputusan secara terbuka akan dapat meningkatkan kinerja dari karyawannya (Insan \& Yuniawan, 2016). Gaya kepemimpinan demokratis ke otoriter sangat dipengaruhi oleh pengalaman seseorang terhadap kehidupan pribadi pada dirinya (Nursalam, 2011).

Tujuan penulisan secara sistematis meninjau penelitian empiris yang dipublikasikan tentang gaya kepemimpinan untuk meningkatkan kinerja perawat dan jenis kepemimpinan yang bisa meningkatkan kinerja perawat di ruang rawat inap?

\section{METODE}

Melakukan tinjauan sistematis melalui review jurnal tentang gaya kepemimpinan dan kinerja perawat di rawat inap. Strategi pencarian data dari google scholar dan ProQuest. Kriteria kelayakan studi pada penelitian melibatkan penelitian empiris dan merujuk pada gaya kepemimpinan, kinerja perawat dalam keperawatan di RS. Kualitas penelitian dinilai dengan instrumen terstruktur berdasarkan desain penelitian.

Prosedur ekstraksi data dilakukan dari hasil penelusuran artikel di ProQuest, Google Scholar, Sinta (Science and Technology Index) didapatkan 631 artikel, kemudian di buat kriteria artikel 5 tahun terakhir terbit dan ada duplikasi sejumlah 201. Kemudian dilakukan pencarian artikel yang lengkap sejumlah 299 dan artikel yang tidak lengkap tidak digunakan. Artikel yang lengkap dipilih dengan menggunakan kata kunci gaya kepemimpinan dan kinerja perawat dengan teks lengkap terdapat 12 artikel.

\section{HASIL DAN PEMBAHASAN}

Pencarian mengidentifikasi 631 kutipan. Kemudian disaring 99 artikel teks lengkap untuk kelayakan, 12 diantaranya dimasukkan dalam penelitian ini.

Gambar 1. Diagram alir proses seleksi studi

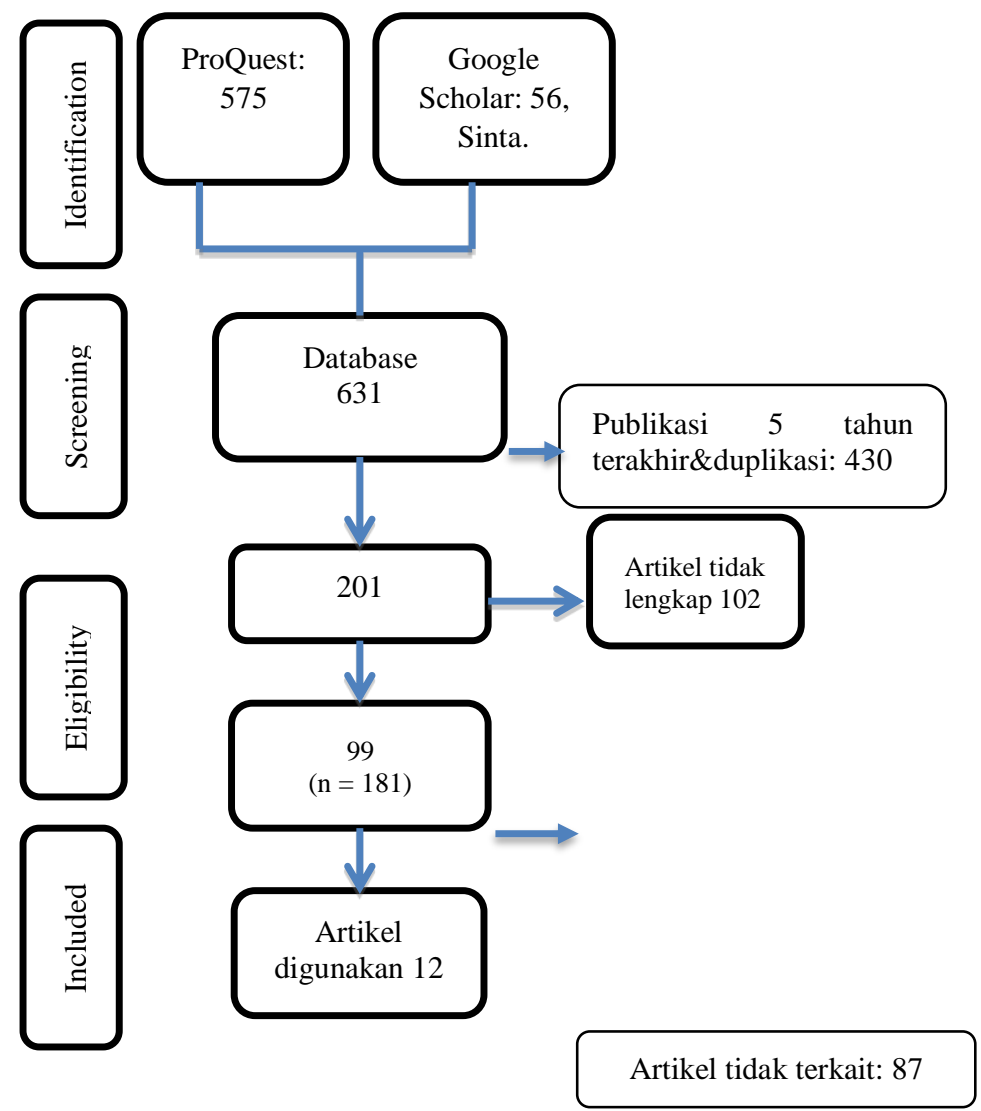

Peningkatan kinerja akan membawa kemajuan bagi suatu institusi, oleh karena itu upaya untuk meningkatkan kinerja dengan gaya kepemimpinan merupakan tantangan manajemen yang serius untuk mencapai tujuan dan kelangsungan suatu institusi yang tergantung pada kualitas kinerja sumber daya manusia yang ada di dalamnya.

\section{a. Gaya kepemimpinan demokrasi}

Gaya kepemimpinan yang paling banyak digunakan di ruang 
keperawatan anak adalah kepemimpinan demokratis, sedangkan kepemimpinan otoriter paling banyak di gunakan di ruang bedah. Kaitannya gaya kepemimpinan dengan motivasi kerja, motivasi tinggi perawat dalam bekerja lebih banyak didominasi gaya kepemimpinan demokratis, dan kepemimpinan otoriter menyebabkan perawat memiliki motivasi kerja yang rendah (Nurfadillah, 2013).

Pada penelitian Roostyowati, mayoritas responden menyatakan puas dengan kepemimpinan demokratis selama bekerja sebagai perawat di RS. Gaya kepemimpinan yang menghargai sifat dan kemampuan dari staf serta mampu memotivasi staf dan kelompok untuk mencapai tujuan adalah kepemimpinan demokratis (Roostyowati, 2015). Gaya kepemimpinan demokratis memberi kontribusi dengan kinerja perawat yang baik. Salah satu upaya meningkatkan kinerja organisasi dengan perbaikan pada kinerja karyawan baik individu maupun kelompok (Zulkarnain et al., 2017). Gaya kepemimpinan demokratis adalah kemampuan mempengaruhi orang lain agar mau bekerja sama untuk mencapai tujuan yang telah ditetapkan dengan cara berbagai kegaiatan yang akan dilakukan dan ditentukan bersama antara pemimpin dan bawahan (Buanasari \& Ratulangi, 2019), (Habibi et al., 2019), (Yanti, 2019).

Dan kemampuan pimpinan efektif yaitu seorang pemimpin yang mampu membangkitkan semangat kerja dan mampu menyatukan usaha banyak pekerja dengan bermacam - macam ketrampilan (Mujisari Tri Rahayu, Tavip Dwi Wahyuni, 2018).

\section{b. Gaya kepemimpinan otoriter}

Hasil penelitian yang dilakukan di RSJD Dr. Aminogondo Hutomo Provinsi Jawa Tengah tahun 2017 gaya kepemimpinan otoriter banyak digunakan di ruang rawat inap. Pengambilan keputusan dengan gaya kepemimpinan baik perencanaan dan wewenang bersifat satu arah adalah kepemimpinan otoriter. Apabila ada permasalahan, kepala ruang membuat perencanaan, kepala ruang membuat keputusan berdasarkan wewenang sendiri (Windi Yunita Siwi, Titik Suerni, 2017).

Gaya kepemimpinan otoriter adalah gaya kepemimpinan dimana kekuasaan atau wewenang sebagian besar mutlak pada pimpinan. Pemimpin yang memiliki gaya kepemimpinan otoriter atau sentralisasi wewengan dalam setiap pengambilan keputusan atau kebijakan tidak melibatkan bawahan. Fokus kepemimpinan hanya pada peningkatan produktivitas kerja tanpa memperhatikan perasaan dan kesejahteraan bawahan. (Diah Aryanti Sapto Warsi, Lilik Siswanta, Endang Tri Wahyuni, 2020)

\section{c. Gaya kepemimpinan kompilasi}

Motivasi perawat dan
kepemimpinan kepala ruang
mempengaruhi budaya keselamatan
pasien. Variabel yang paling
mempengaruhi penerapan budaya
keselamatan pasien adalah gaya
kepemimpinan. Sebagian besar
responden berpersepsi bahwa gaya
kepemimpinan kepala ruang yang
efektif menerapkan kepemimpinan
tertentu untuk memenuhi prinsip-


prinsip di dalam kepemimpinannya, yaitu bersifat suportif, direktif, partisipatif, orientasi prestasi, serta mampu mengenali kebutuhan bawahan dan memberikan reward atas keberhasilan dalam pencapaian tujuan (Nivalinda et al., 2013).

Hasil penelitian pada pengaruh gaya kepemimpinan kepala ruangan terhadap kinerja perawat menghasilkan tidak ada pengaruh yang signifikan, gaya kepemimpinan kepala ruang belum memberikan kontribusi yang bermakna dalam penampilan kinerja perawat. Ada hubungan yang signifikan antara gaya kepemimpinan kepala ruangan terhadap kinerja staf perawat (Jihad, 2012). Dalam penelitian ini indikator variabel yang dipakai adalah gaya kepemimpinan yang meliputi gaya memberikan informasi (telling), membimbing (selling), berperan serta (participation) dan pendelegasian (delegating) (Artiningsih, 2016).

Gaya kepemimpinan kombinasi yang diterapkan merupakan kombinasi dari gaya kepemimpinan direktif, konsultatif, partisipatif dan delegatif. Gaya kepemimpinan konsultatif lebih dominan digunakan oleh pimpinan dalam berkomunikasi dengan bawahannya yang menggambarkan dukungan dengan bawahan tinggi dan pengarahan yang tinggi, dapat disimpulkan gaya kepemimpinan ini diterapkan oleh pimpinan karena bawahan telah termotivasi dan berpengalaman dalam menghadapi suatu tugas. Namun demikian, pimpinan juga mengkombinasikan gaya yang digunakannya, disesuaikan dengan kondisi dan situasi (Harlen \& Lousyiana, 2015).

Kecenderungan gaya kepemimpinan otoriter dan demokratik mampu memberikan kinerja yang baik dan cukup. Jadi, tidak ada gaya kepemimpinan yang tidak baik atau buruk. (Lubis et al., 2017) Gaya kepemipinan yang baik mampu memadukan gaya kepemimpinan otoriter, demokratik. Bawahan memerlukan pengawasan dari pimpinan terkait instruksi dan situasi darurat, dan bawahan perlu dilibatkan dalam pengambilan keputusan. Sebaliknya pimpinan juga membutuhkan bawahan yang mampu dan mau diajak bekerjasama dalam menyelesaikan tugas dan masalah.

\section{d. Gaya kepemimpinan Konsultasi}

Gaya kepemimpinan konsultasi digunakan karena gaya kepemimpinan yang dilakukan ada pengawasan wajar, tidak terlalu longgar maupun ketat. Dalam memberikan pelayanan keperawatan ada sesi diskusi bersama perawat yang melakukan, menjelaskan dan mengarahkan lebih banyak daripada menginstruksikan. Hasil kinerja dan komunikasi lebih efektif dan optimal (Alvin Nur Fadhilah, Ana Zakiyah, 2019).

Penelitian menemukan bahwa manajer perawat menggunakan semua empat gaya kepemimpinan teori Leadership, tergantung pada situasinya. Namun, gaya kepemimpinan yang paling sering digunakan adalah gaya kepemimpinan yang berorientasi prestasi. Gaya kepemimpinan partisipatif dan gaya kepemimpinan direktif adalah yang paling jarang digunakan oleh manajer perawat. Ini berarti bahwa manajer perawat menunjukkan pendekatan kepemimpinan situasional tanpa menempel pada gaya kepemimpinan tertentu (Asamani et al., 2016). Teori kepemimpinan situasional 
mengemukakan bahwa seseorang menggunakan gaya kepemimpinan pada perilaku dan keterampilan tergantung pada tim mereka yaitu dilihat dari tingkat pengalaman, pengetahuan, kompetensi, kemauan dan kemampuan. Pendekatan ini didasarkan pada kombinasi empat gaya kepemimpinan (Style, 1967).

\section{KESIMPULAN}

Kepemimpinan adalah konsep penting dalam keperawatan, bahkan dalam hal kecil dan sangat rumit. Gaya kepemimpinan yang tepat diperlukan untuk menghindari pemborosan, kebingungan, dan kesalahan. Gaya kepemimpinan memiliki pengaruh positif dan signifikan terhadap kinerja. Maka tinggi rendahnya kinerja perawat dapat dijelaskan oleh gaya kepemimpinan. Berpengaruhnya gaya kepemimpinan secara langsung terhadap kinerja perawat, menggambarkan gaya kepemimpinan cukup optimal diterapkan oleh pimpinan dalam berkomunikasi dengan bawahannya. Gaya kepemimpinan yang tepat diperlukan untuk menghindari pemborosan, kebingungan, dan kesalahan.

\section{REFERENSI}

Alvin Nur Fadhilah, Ana Zakiyah, E. N. S. (2019). Hubungan Gaya Kepemimpinan Kepala Ruangan Dengan Kepatuhan Perawat Dalam Melaksanakan Tindakan Pemasangan Infus di RSI Sakinah Kabupaten Mojokerto. Journal of Chemical Information and Modeling, 53(9), 1689-1699.

https://doi.org/10.1017/CBO97811074 15324.004

Artiningsih, D. W. (2016). Hubungan Gaya Kepemimpinan Kepala Ruangan,
Motivasi dan Disiplin Terhadap Kinerja Perawat di RSUD Brigjen $H$. Hasan Basry Kndangan Kalimantan Selatan. 9(1), 87-104.

Asamani, J. A., Naab, F., \& Ofei, A. M. A. (2016). Leadership styles in nursing management: implications for staff outcomes. Journal of Health Sciences, 6(1), 23-36. https://doi.org/10.17532/jhsci.2016.266

Buanasari, A., \& Ratulangi, U. S. (2019). Hubungan Gaya Kepemimpinan Kepala Ruangan Dengan Kinerja Perawat Di Ruang Rawat Inap Rumah Sakit Gmim Pancaran Kasih Manado. Jurnal Keperawatan, 7(1), 1-8.

Diah Aryanti Sapto Warsi, Lilik Siswanta, Endang Tri Wahyuni, S. (2020). Analisis pengaruh gaya kepemimpinan, kepuasan kerja terhdapa kinerja tenaga kependidikan. Bisman, 3(1), 1-12.

Fahlevi, M. I. (2017). Pengaruh Kompetensi Petugas Terhadap Kinerja Pelayanan Kesehatan Dipuskesmas Peureumeue kabupaten Aceh Barat. 978-979. http://eprints.uad.ac.id/5421/1/34.

PENGARUH KOMPETENSI PETUGAS TERHADAP KINERJA PELAYANAN KESEHATAN DIPUSKESMAS PEUREUMEUEKABUPATEN ACEH BARAT.pdf

Habibi, A., Giyanti, U., Sriningsih, N., Ilmu, F., Universitas, K., \& Tangerang, M. (2019). Hubungan gaya kepemimpinan kepala ruangan dan motivasi kerja dengan kinerja perawat di ruang rawat inap RS An-nisa Tangerang. 2(2), 6580.

Harlen, \& Lousyiana, T. T. (2015). Pengaruh Gaya Kepemimpinan Dan Budaya Organisasi Terhadap Kepuasan Kerja Dan Kinerja Perawat Di Rumah Sakit Islam Ibnu Sina Pekanbaru. Tepak 
Manajemen Bisnis, 7(3), 509-521.

Hasibuan, Malayu, S. P. (2007). Manajemen Sumber Daya Manusia, edisi revisi, Bumi Aksara. Bumi Aksara.

Insan, P. D., \& Yuniawan, A. (2016). Problems that occur in hospitals Tugurejo Semarang is employee performance of nursing less than the maximum. It is shown from the number of complaints from customers who go into the hospital management Tugurejo Semarang where most complaints are directed. 5(2007), 1-13.

Jihad, K. (2012). Pengaruh Gaya Kepemimpinan Kepala Ruangan dan Disiplin Kerja Terhadap Kinerja staf Perawat di RSUD Buntok KalimantanTengah,Tesis Program Magister Manajemen Sekolah Tinggi Ilmu Ekonomi (STIE).

Lubis, M. amalia, Nasution, N., Omanzah, O., \& Maizura, T. (2017). Hubungan Antara Gaya Kepemimpinan Kepala Ruangan Dengan Kinerja Perawat Ruang Rawat Inap Di Rumah Sakit Otorita Batam. Zona Kesehatan: Jurnal Ilmu Kesehatan, 11(3), 26-32.

Mujisari Tri Rahayu, Tavip Dwi Wahyuni, S. (2018). Hubungan Antara Gaya Kepemimpinan Kepala Ruangan dengan Kinerja Perawat Pelaksana di Rumah Sakit Islam Gondanglegi Kabupaten Malang. 3, 785-790.

Nivalinda, D., Hartini, M. C. I., \& Santoso, A. (2013). Pengaruh Motivasi Perawat dan Gaya Kepemimpinan Kepala Ruang Terhadap Penerapan Budaya Keselamatan Pasien Oleh Perawat Pelaksana Pada Rumah Sakit Pemerintah di Semarang. 1(2), 138145.

Nurfadillah. (2013). Hubungan Gaya Kepemimpinan Kepala Ruangan
Dengan Motivasi Kerja Perawat di Ruang Perawatan RSUD Syekh Yusuf Kab. Gowa.

Nursalam. (2011). Manajemen keperawatan aplikasi dalam praktik keperawatan professional. Salemba Medika.

Roostyowati, R. (2015). Hubungan gaya kepemimpinan kepala ruang dengan kepuasan kerja perawat pelaksana di RS Panti Waluyo Sawahan Malang. Jurnal Care, 3(1), 9-13.

Sedarmayanti. (2008). Manajemen Sumber Daya Manusia, Reformasi Birokrasi dan Manajemen pegawai Negeri. PT. Refika Aditama.

Style, R. W. (1967). The 3D management style theory: the current state and future expectations. Consulting Psychology Journal: Practice and Research. 21, 4, 8-17.

Windi Yunita Siwi, Titik Suerni, B. W. (2017). Hubungan Gaya Kepemimpinan Kepala Ruang Terhadap Tingkat Stres Pada Perawat Pelaksana di Ruang Rawat Inap RSJD Dr. Aminogpndo Hutomo Provinsi Jawa Tengah.

Yanti, D. dan. (2019). Hubungan Gaya Kepemimpinan Kepala Ruangan terhadap Kinerja Perawat Pelaksana di Ruang Rawat Inap RSUD Kota Bekasi.

Zulkarnain, D., Syah, R., Nofiyanto, M., In, L., Departement, N., Jenderal, S., Yani, A., Ambarketawang, B., \& Sleman, G. (2017). Upaya peningkatan kinerja perawat gawat darurat melalui berbagai gaya kepemimpinan di RSUD daerah istimewa Yogyakarta. 6(3), 186-194. 